\title{
Features Exterior of Cattle of Breed Limousian in the Period of Their Acclimation in the Conditions of the Northern Trans-Ural
}

\section{A A Bakharev'1,2, O M Sheveleva1, M A Chasovshchikova1', N A Sadomov³ A P Duktov ${ }^{3}$, A I Litkevich¹, B Zh Bugasov¹, and A M Akhmetov ${ }^{1}$}

${ }^{1}$ Northern Trans-Ural SAU

${ }^{2}$ SRIA for NTUR - Branch of Tyumen Scientific Centre SB RAS

${ }^{3}$ The Belarusian State Agricultural Academy

\section{Abstract}

The paper presents a characteristic of the exterior features of the specialized limousin meat breed bred in the conditions of the Tyumen region. Studies were conducted on first-calf cows of different generations of animals. At the same time, the introduced animals belong to the zero generation, their descendants to the 1st generation, and the grandchildren belong to the 2 nd genetic-ecological generation. In the process of research, it was that the acclimatization process left its mark on the manifestation of

Corresponding Author:

A A Bakharev

salers@mail.ru

Received: 25 October 2019

Accepted: 15 November 2019

Published: 25 November 2019

Publishing services provided by Knowledge E

(c) A A Bakharev et al. This article is distributed under the terms of the Creative Commons Attribution License, which permits unrestricted use and redistribution provided that the original author and source are credited.

Selection and Peer-review under the responsibility of the AgroSMART 2019 Conference Committee.

\section{G OPEN ACCESS} the main breeding and productive qualities of the studied livestock generations. One of the manifestations of which was a certain grinding of cows of the first generation. The obtained results of the exterior assessment of cows of different generations showed that the best exterior development was observed in cows of the second and zero generation. So, in cows of the first and second generations there was a decrease in measurements of the chest, estimated by the chest index by 1.1--3.1\% (P> 0.999), with an increase in the proportions characterizing the development of meat qualities of animals by 6.2--6.6 \% ( $P>0.999$ ). Adaptation to new conditions confirms the development of such indices as the typical physique and severity of type, which, when changing generations, had an increase dynamic.

Keywords: Beef cattle, breed limousine, exterior, body measurements, generations of animals.

\section{Introduction}

Every year, many cattle are imported into Russia from abroad, while the problem of adaptation and acclimatization of imported animals to new environmental, climatic and economic conditions is of particular relevance [1--3].

Until recently, beef cattle breeding was aimed at the use of precocious, compact animals raised on high-energy diets with a high proportion of concentrated feed. But at present, the production requirements in relation to the economically useful qualities of 
beef cattle have changed towards large animals that are able to add live weight for a long time due to the intensive growth of muscle tissue with low fat deposition $[4,5]$.

Limousine animal breeds, which differ in rather high productive qualities with good acclimatization abilities [6], are more likely to meet these requirements.

\section{Methods and Equipment}

In our studies, we analyzed changes in the exterior features of limousin cattle in the process of their acclimatization in the context of several generations (three genetic and environmental generations). Moreover, imported animals belong to the zero generation, their descendants to the 1st generation, and grandchildren belong to the 2 nd geneticecological generation [7].

\section{Results}

Assessment of the exterior features of animals was studied based on taking measurements from the corresponding articles of the exterior according to generally accepted methods. Measurements of measurements were made during the scoring of livestock in cows after the first calving at the age of 3 years (table 1).

TABLE 1: Body measurements of cows of the first lactation of the Limousin breed $(\bar{X} \pm S \bar{x}), \mathrm{cm}$.

Survey
Number of animals, head
Height at the withers
Sacral height
Chest depth
Chest width
Macloc width
Width in ischial tubercles
Oblique body length
Oblique back length
Chest circumference
Back half-girth
Skin thickness

\begin{tabular}{|c|c|c|}
\hline \multicolumn{3}{|c}{ Genetic and ecological generation } \\
zero & first & second \\
\hline 138 & 189 & 45 \\
\hline $127,1 \pm 0,41$ & $124,8 \pm 0,37^{* * *}$ & $125,2 \pm 0,85^{*}$ \\
\hline $133,3 \pm 0,40$ & $131,7 \pm 0,39^{* *}$ & $132,4 \pm 1,25$ \\
\hline $63,3 \pm 0,38$ & $62,3 \pm 0,32^{*}$ & $63,1 \pm 0,81$ \\
\hline $41,6 \pm 0,36$ & $39,6 \pm 0,31^{* * *}$ & $40,8 \pm 0,90$ \\
\hline $46,5 \pm 0,29$ & $45,7 \pm 0,36$ & $47,1 \pm 0,98$ \\
\hline $34,8 \pm 0,17$ & $34,6 \pm 0,17$ & $35,8 \pm 0,46^{*}$ \\
\hline $148,3 \pm 0,80$ & $147,6 \pm 0,68$ & $148,5 \pm 1,57$ \\
\hline $48,1 \pm 0,28$ & $46,9 \pm 0,25^{* *}$ & $49,5 \pm 0,55^{*}$ \\
\hline $194,8 \pm 0,78$ & $191,6 \pm 0,66^{* *}$ & $192,5 \pm 1,99$ \\
\hline $115,3 \pm 0,33$ & $118,7 \pm 0,48^{* * *}$ & $121,3 \pm 0,41^{* * *}$ \\
\hline $0,59 \pm 0,01$ & $0,62 \pm 0,01^{*}$ & $0,68 \pm 0,01^{* * *}$ \\
\hline
\end{tabular}

Note: hereinafter, where ${ }^{*} \mathrm{P}>0.95 ;{ }^{* *} \mathrm{P}>0.99 ;{ }^{* * *} \mathrm{P}>0.999$ in comparison to cows of zero G.E. 
Exterior performance in cows after the first calving, in the context of several generations, shows the wave-like dynamics of changes in the general proportions of the physique during generational change. This was manifested in a certain decrease in altitude, latitude, and chest measurements, with an increase in the proportions characterizing the development of the back of the trunk and the thickness of the skin. At the same time, it was noted that the cows of the first generation in almost all the analyzed parameters of the exterior were inferior to their peers of zero generation.

Thus, the grinding of cattle in the first generation with respect to zero generation in height at the withers was $2.3 \mathrm{~cm}(1.8 \%, \mathrm{P}>0.999)$, and already the second-generation cows reduced this difference to $1.9 \mathrm{~kg}(1.5 \%, \mathrm{P}>0.95)$. The height in the sacrum of cows of the first generation was also already minimal and amounted to $131.7 \mathrm{~cm}$, giving way to zero generation by $1.6 \mathrm{~cm}(1.2 \%, \mathrm{P}>0.99)$, and animals of the second generation in this indicator were almost at the level with representatives of imported animals. For breast measurements, a significant difference was noted between the first and zero generations in favor of the latter with a difference of 1.0--3.2 cm (1.6--4.8 \%, P> 0.95 -0.999).

An important feature in the adaptation of livestock to new conditions was an increase in latitudinal measurements characterizing the development of the pelvis in cows of the second generation. In width in maclocs, differences were noted between the second and first generation by $1.4 \mathrm{~cm}(3.1 \%, P>0.95)$, and in width in the ischial tubercles, cows of the second generation exceeded the zero and the first generation by $1.0--1.2 \mathrm{~cm}$ (2.9--3.5\%, P> 0.95). The indicator characterizing the length of the pelvis was also on the side of the second-generation cows with a similar difference of 1.4--2.6 cm (2.9--5.5 $\%, P>0.95--0.99$ ).

The meat advantages of animals during life in absolute terms can be estimated by measuring the half-girth of the rear, which was less pronounced in imported cows 115.3 $\mathrm{cm}$, significantly inferior to the first and second generation cows by $3.4 \mathrm{~cm}(2.9 \%)$ and $6 \mathrm{~cm}$ (5.2\%), respectively, P>0.999. With the change of generations in the process of acclimatization, cows developed a protective mechanism of adaptation against cold exposure, which is estimated by the thickness of the skin. This indicator had a higher value in the second- and first-generation cows of 0.68 and $0.62 \mathrm{~cm}$, while the zero generation cows were $15.2 \%(P>0.999)$ and $5.1 \%(P>0,95)$.

The results can be explained by the fact that in the first generation the development of heifers when moving to new conditions was delayed by stress factors and adaptation. The offspring received from them was more adapted to new conditions and restored the exterior parameters characteristic of this breed. 
When comparing the correspondence of the exterior parameters of cows with standard values, based on the methodology for testing for distinctness, uniformity and stability [8], some inconsistency of the exterior indicators in the analyzed generations was noted (Fig. 1).

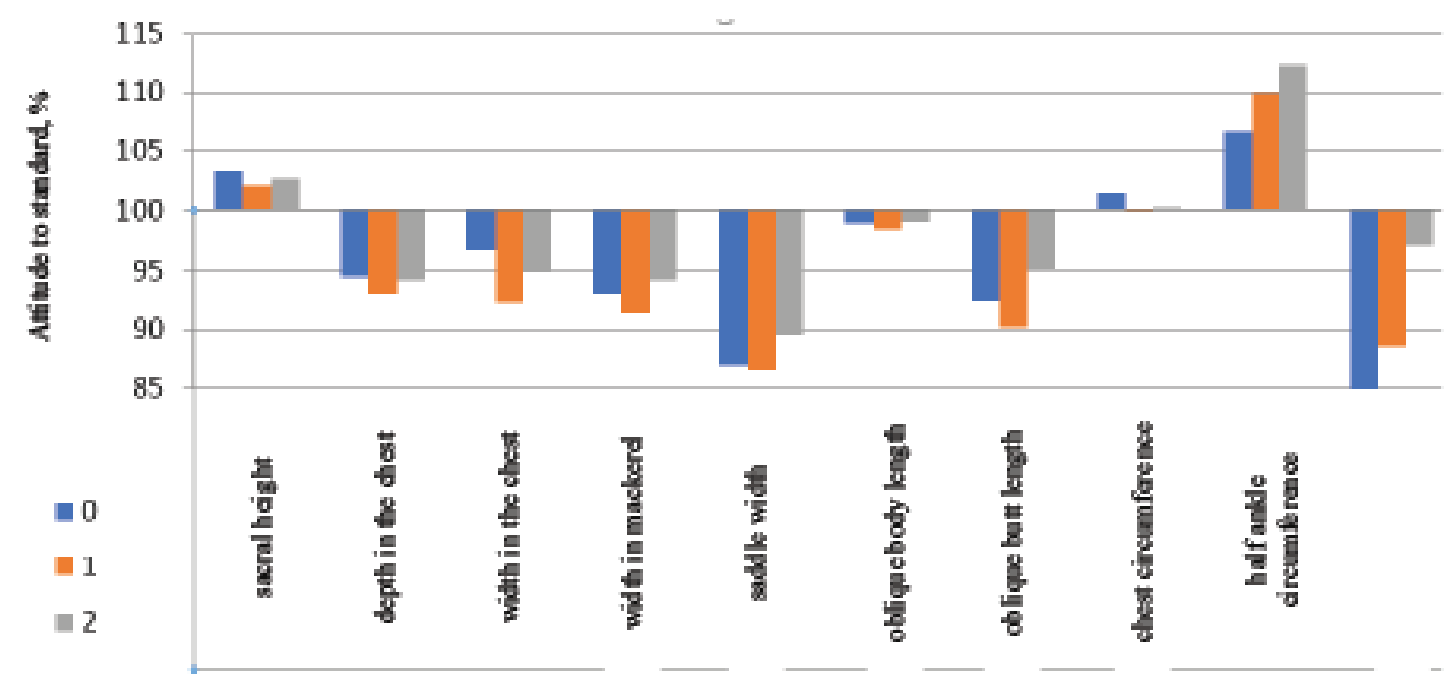

Figure 1: Correspondence diagram of body parameters of Limousin cows with average recommended by breed.

The greatest deviation from the recommended parameters in the undesirable direction was noted for all latitudinal measurements, and the width in the ischial tubercles had a higher underdevelopment reaching up to $10.5--13.5 \%$ of the norm. The development of the chest in the depth and length of the pelvis also did not correspond to the average standard indicators of about 5.5--9.8\%. However, if we compare the measurements with the lower boundary of the recommended indicator, the difference is about 1--3 $\mathrm{cm}$, depending on the generation. So, for example, the thickness of the skin lags the average recommended range by $2.9-15.7 \%$, but fully corresponds to the lower limit of the norm.

All generations of the studied animals were characterized by high growth, which is confirmed by measuring the height in the sacrum, which was $2.1-3.3 \%$ higher than the average, as well as the good development of the posterior third of the trunk, characterized by a half-circumference of the back with an excess of the norm of 6.8-$12.3 \%$, but within the upper limit of the recommended range. The remaining exterior physique parameters were in line with the recommended norm.

The obtained results of the exterior assessment of cows of different generations showed that the best exterior development was observed in cows of the second and zero generation. 
Body measurements in enough form do not allow to assess the growth and development of animals. A more detailed description of the physique of the animal and the proportionality of the development of the compared generations are given by the indices of the physique (Table 2).

TABLE 2: Body indices of first-calf cows of breed Limousine $(\bar{X} \pm S \bar{x}), \%$.

\begin{tabular}{l|c|c|c|}
\hline Index & \multicolumn{3}{|c}{ Genetic and ecological generation } \\
\hline & zero & first & second \\
\hline Leggy & $50,2 \pm 0,23$ & $50,1 \pm 0,21$ & $49,6 \pm 0,68$ \\
\hline Stretch & $116,7 \pm 0,48$ & $118,3 \pm 0,50^{*}$ & $118,6 \pm 1,34$ \\
\hline Breast & $65,8 \pm 0,59$ & $63,7 \pm 0,39^{* *}$ & $64,7 \pm 1,18$ \\
\hline Pelvic & $89,5 \pm 0,80$ & $86,7 \pm 0,73^{*}$ & $86,6 \pm 1,47$ \\
\hline Blockiness & $131,4 \pm 0,49$ & $129,8 \pm 0,53^{*}$ & $129,6 \pm 1,66$ \\
\hline Overgrown & $104,9 \pm 0,21$ & $105,5 \pm 0,17^{*}$ & $105,8 \pm 0,70$ \\
\hline Massiveness & $153,3 \pm 0,50$ & $153,5 \pm 0,58$ & $153,8 \pm 1,56$ \\
\hline Broad bodies & $21,4 \pm 0,13$ & $20,7 \pm 0,16^{* *}$ & $21,2 \pm 0,41$ \\
\hline Meatiness & $90,7 \pm 0,27$ & $95,1 \pm 0,33^{* * *}$ & $96,9 \pm 0,85^{* * *}$ \\
\hline Body type & $689,1 \pm 2,47$ & $689,0 \pm 3,67$ & $718,3 \pm 9,12^{* *}$ \\
\hline Type Expressions & $112,6 \pm 0,55$ & $113,9 \pm 0,62$ & $114,7 \pm 1,54$ \\
\hline
\end{tabular}

Animals of all analyzed generations were distinguished by long-leggedness, with the value of this index above the recommended up to $8 \%$, with a compact physique. Zerogeneration cows had a less pronounced extension index of $116.7 \%$, yielding $1.6 \%$ (P> 0.95 ) and $1.9 \%$ behind the first and second generation. Indicators characterizing the development of breast proportions of the physique were on the side of the imported animals, with less pronounced values in the first generation, obtained under new conditions. So, the cows of the first generation were inferior to the imported animals by the chest index by $2.1 \%(P>0.99)$, the pelvic and pedigree by $2.8 \%(P>0.95)$ and the body by $0.7 \%(P>0,99)$. The cows of the next generation (second generation), the indices of these indices were closer to zero generation. But it should be noted that cows of all generations in terms of severity of the thoracic index corresponded to cattle of the combined direction of productivity.

The incidence index, which characterizes the volume and length of the physique, was also on the side of zero generation, with a difference to the younger generations by 1.6$-1.8 \%(P>0.95)$. But local generations had an advantage in such indices as overgrowing and meatiness, where cows of the second generation showed a more pronounced sign value. 
The cows of the first generation in terms of meat index compared to the maternal generation improved their indicators by $4.4 \%$ ( $P>0.999)$, and the granddaughters of imported animals by $6.2 \%(P>0.999)$.

\section{Conclusion}

The research results showed that the acclimatization process has left its mark on the manifestation of the main breeding and productive qualities of the studied livestock generations. One of the manifestations of which was a certain grinding of cows of the first generation. Adaptation to new conditions confirms the development of such indices as the typical physique and severity of type, which, when changing generations, had an increase dynamic. Similar research results are consistent with studie sobtained previously [9--12].

\section{Funding}

This work was supported by a grant from the President of the Russian Federation MD2403.2018.11 Agreement No. 075-15-2019-097.

\section{Acknowledgement}

The authors would like to thank their colleague for their contribution and support to the research. They are also thankful to all the reviewers who gave their valuable inputs to the manuscript and helped in completing the paper.

\section{Conflict of Interest}

The authors have no conflict of interest to declare.

\section{References}

[1] Dunin, I., Sharkaev V., Kochetkov, A. (2011). Results of the functioning of the beef cattle breeding industry in the Russian Federation. Dairy and beef cattle breeding, no. 5, pp. 2--4.

[2] Gordeev, A.V. (2009). State program for the development of agriculture: the first year of implementation. Agrarian Bulletin of the Urals, no. 1, pp. 4--8. 
[3] Islamov, R.R., Kamaldinov, I.N. (2011). Features of the exterior and development of cows of meat breeds in the farms of the Republic of Tatarstan. Scientific notes of the Kazan State Academy of Veterinary Medicine named after N.E. Bauman, no. 207, pp. 220--224.

[4] Kosilov, V.I., Mironenko, S.I., Salikhov, A.A. (2010). Rational use of genetic resources of red steppe cattle for beef production with thoroughbred breeding and crossbreeding. Moscow: White Beach, $452 \mathrm{p}$.

[5] Zadnepryansky, I.P., Kosilov, V.I., Zhaimysheva, S.S., Shvyndenkov, V.A. (2012). Features of the growth and development of gobies of meat, combined breeds and their crosses. Bulletin of the Orenburg State Agrarian University, no. 6, pp. 105--107.

[6] Sheveleva, O.M., Bakharev, A.A. (2013). Formation of the industry of cattle meat using French breeds in the conditions of the Northern Trans-Urals. Agrarian Bulletin of the Urals, no. 8, pp. 23--25.

[7] Prakhov, L.P., Chernov, G.A. (1977). Guidelines for the study of acclimatization abilities of beef cattle. Orenburg, $24 \mathrm{p}$.

[8] Dunin, I.M., Blokhin, V.I., Dzhaparidze, T.G., Tyurikov, V.M., Milovanov, L.V., Spivak, M.G. (1997). Collection of legal and regulatory acts to the federal law "On selection achievements". Moscow: VNIlplem, iss. 1, 204 p.

[9] Bakharev, A.A., Sheveleva, O.M., Fomintsev, K.A., Grigoriev, K.N., Bugasov, B.Zh. (2018). Productive Qualities of Beef Cattle Breeds in the conditions of the Southern Trans-Urals. International scientific and practical conference "AgroSMART -- Smart solutions for agriculture" (AgroSMART 2018). Retrieved from: https://doi.org/10.2991/ agrosmart-18.2018.8

[10] Bakharev, A.A., Sheveleva, O.M., Aleksandrova, S.S., Renev, E.P., Koshchaev, A.G. (2018). Conformation Traits of Salers Cattle of Different Genetic and Ecological Generations. International scientific and practical conference "AgroSMART -- Smart solutions for agriculture" (AgroSMART 2018). Retrieved from: https://doi.org/10.2991/ agrosmart-18.2018.9

[11] Chasovshchikova, M.A., Sheveleva, O.M., Svjazhenina, M.A. et al. (2017). Relationship between the genetic variants of kappa-casein and prolactin and the productivebiological characteristics of cows of the black-motley breed. Journal of Pharmaceutical Sciences and Research, vol. 9, no. 7, pp. 1038--1044.

[12] Bakharev, A.A., Sheveleva, O.M., Fomintsev, K.A. et al. (2018). Biotechnological Characteristics of Meat Cattle Breeds in the Tyumen Region. J. Pharm. Sci. \& Res., vol. 10(9), pp. 2383--2390. 